THE JOURNAL OF INFECTIOUS DISEASES - VOL. 155, NO. 1 - JANUARY 1987

(c) 1987 by The University of Chicago. All rights reserved. 0022-1899/87/5501-0018\$01.00

\title{
Human Immune Response to Giardia lamblia Infection
}

The protozoan intestinal parasite Giardia lamblia is the most commonly found pathogenic parasite in Western countries and is endemic in much of North America [1]. Transmission of $G$. lamblia can be from person to person [2] but is more commonly waterborne, a result of the relative resistance of the organism's cysts to chlorination [3].

Clinical giardiasis ranges from asymptomatic carriage to an illness characterized by diarrhea and abdominal cramps. The disease is usually self-limited, with a mean duration of six weeks, although some patients go on to a protracted illness characterized by malabsorption and debilitation [1]. Immune mechanisms are thought to be important in giardiasis; second infections are rare, and persons with congenital common variable hypogammaglobulinemia frequently fail to clear the infections [4]. Giardia-specific IgG has also been detected in patients' sera [5].

It has only been recently, with the development of a medium to support axenic culture [6], that giardia antigens have been studied in any detail. To date, no reports have been published that examine the serological response of natural infection to giardia protein fractions. We undertook this study to elucidate the major antigenic determinants of Giardia under conditions of natural human infection. We were able to demonstrate, by using an immunoblotting technique, a protein antigen that may be specifically recognized during infection.

\section{Materials and Methods}

Patients and controls. Sera were obtained from $16 \mathrm{pa}-$ tients with Giardia in their feces at the time of blood sampling. The patients ranged in age from three to 76 years; there were eight males and seven females. Ten of these patients acquired their infections in western Canada (Alberta or British Columbia), two acquired their infections in Asia, three in Africa, and one in the Soviet Union. All foreignacquired infections were detected within two weeks of the patient's return, during screening at a posttravel self-referral clinic. Locally acquired infections were detected largely through monitoring of diagnostic laboratory reports.

Control sera were obtained from 10 healthy persons (office workers and laboratory personnel not working with Giardia), all long-term residents of Canada with no his-

Received for publication 24 March 1986, and in revised form 8 July 1986.

This work was supported by grants from the Alberta Environment Research Trust and from the University of Alberta Hospitals Special Services.

We thank R. Meuser for technical assistance.

Please address requests for reprints to Dr. W. M. Wenman, Department of Pediatrics, 2C3.00 Walter MacKenzie Center, University of Alberta, Edmonton, Canada T6G 2R7. tory of giardiasis and no history of symptomatic gastrointestinal disease for the preceding two years. Asymptomatic carriage of Giardia was not specifically excluded.

Three patients had common variable hypogammaglobulinemia and no detectable serum IgA. All of these three patients had chronic diarrhea associated with Giardia, with a duration of symptoms ranging from two to 25 years. Thirteen patients had no history of immune defect. Of these, 11 had acute giardiasis (diarrhea alone in 10, diarrhea and vomiting in one), with a duration of symptoms of two weeks to four months. One patient was asymptomatic but was found to carry Giardia upon return from a visit to Africa. One patient, a 76-year-old man receiving long-term corticosteroid therapy for chronic obstructive lung disease, had had diarrhea for at least six months. All of the patients had concomitant bacterial, parasitic, and, in some cases, viral gastrointestinal pathogens excluded. Two patients were suffering from active pulmonary tuberculosis.

Culture technique for Giardia. G. lamblia strain WB, originally isolated from an individual who had acquired his infection in Afghanistan [7], was obtained from Dr. Peter Wallis, Kananskis Center, Calgary, Alberta. The parasites were grown in filter-sterilized TY1-S-33 medium (with the exception that casein digest peptone [BBL Microbiology systems, Cockeysville, Md] was substituted for trypticase, which was found not to support growth) supplemented with $50 \mu \mathrm{g}$ of dehydrated bovine bile and $10 \mathrm{ml}$ of inactivated bovine serum albumin $/ 100 \mathrm{ml}$ of medium [8], with the addition of $150 \mu \mathrm{g}$ of gentamicin $/ \mathrm{ml}$ and $500 \mathrm{U}$ of penicillin $/ \mathrm{ml}$. The organisms were grown in $15-\mathrm{ml}$, screw-top tubes at $37 \mathrm{C}$ and were subcultured every 72-96 hr.

Preparation of antigens. Trophozoites were harvested at $72 \mathrm{hr}$ by cooling culture tubes in ice for $10 \mathrm{~min}$ and then by mechanically dislodging the trophozoites from the glass surface and centrifuging them at $750 \mathrm{~g}$ for $10 \mathrm{~min}$. The trophozoites were washed several times in PBS (pH 7.4) and then resuspended. This supension was then sonicated (model W-220F; Heat Systems Ultrasonics, Plainview, NY; setting, microtip maximum) for 1015 -sec bursts in an ice bath and finally centrifuged at $250 \mathrm{~g}$ for $15 \mathrm{~min}$ to remove debris. We used the method of Lowry et al. [9] to determine the protein content of the sonicated trophozoites.

$S D S-P A G E$. Sonicated trophozoites were placed into a reducing buffer containing $5 \%$ (vol/vol) 2-mercaptoethanol, $10 \%$ (vol/vol) glycerol, $2 \%$ (wt/vol) SDS, and $0.0625 M$ Tris base. Samples were boiled at $100 \mathrm{C}$ for 5 $\mathrm{min}$, and $40 \mu \mathrm{g}$ of protein was applied to each lane. Vertical slab-gel electrophoresis was performed by aligning proteins in a $4.5 \%$ stacking gel and separating them in a $12 \%$ SDS-polyacrylamide gel. Electrophoresis was performed overnight at a constant current of 6 milliamperes. Molecular weight standards included phosphorylase b $(94,000)$, 
bovine serum albumin $(67,000)$, ovalbumin $(43,000)$, carbonic anhydrase $(31,000)$, soybean trypsin inhibitor $(20,100)$, and lactalbumin $(14,400)$, all purchased from Pharmacia (Piscataway, NJ).

Western immunoblotting. Polypeptides were transferred from SDS-polyacrylamide gels by electrophoresis in a Tris-glycine-methanol buffer, as described by Towbin et al. [10]. Electrophoresis was performed for $1 \mathrm{hr}$ at a constant current of 195 milliamperes. The blot was stained with Amido Schwartz and destained; the unsaturated protein-binding sites were then blocked with $5 \%$ ovalbumin. Antisera, in a dilution of 1:100, were reacted with the blots for $16 \mathrm{hr}$ in a $1 \%$ ovalbumin-Tris buffer. The blots were then washed and probed with ${ }^{125}$ I-labeled protein A of Staphylococcus aureus $\left(5 \times 10^{6} \mathrm{cpm}\right.$ per blot) for 2 hr. After washing and air drying, the blots were autoradiographed with Kodak X-Omat AR film (Rochester, NY).

Surface labeling with ${ }^{125} I$. Whole giardia trophozoites were obtained by centrifuging $72-h r$ culture tubes at $750 \mathrm{~g}$ for $10 \mathrm{~min}$ and purifying them as described. Surface labeling with ${ }^{125} \mathrm{I}$ was then performed by the lactoperoxidase method [11]. The labeled trophozoites were sonicated and electrophoresed as described and then autoradiographed by exposure to Kodak X-Omat AR film for $24 \mathrm{hr}$.

\section{Results}

Protein profiles of trophozoites. Coomassie bluestained SDS-polyacrylamide gels of sonicates of strain WB tropozoites (data not shown) revealed a protein profile similar to those obtained by Smith et al. [7]. Although no particular protein appeared to be dominant, several proteins in the molecular weight range of $25,000-40,000$ were prominent.

Analysis of $G$. lamblia antigens. Sera from 13 persons with acute giardiasis and no history of immune defect and sera from three persons with common variable hypogammaglobulinemia were analyzed by immunoblot technique (figure 1). These sera were compared with control sera from 10 normal individuals (data not shown). Although several proteins were found to be antigenic when reacted with sera from infected persons, the dominant antigen was a polypeptide with a molecular weight of 31,000 . This antigen was recognized as the major antigen by 11 of 16 convalescent sera and was often present as a doublet. Of the five weakly reactive or nonreactive sera, two were from immunoglobulin-deficient patients with chronic diarrhea (figure 1, lanes $f$ and $g$ ), and one was from an elderly man receiving long-term corticosteroid therapy (lane k). Sera from most patients with acute giardiasis, whether acquired in North America, Asia, Africa, or Europe, reacted strongly with the protein antigen with the molecular weight of 31,000 . Serum from the asymptomatic patient (lane e) reacted strongly to giardia proteins.

In contrast, sera from 10 control subjects exhibited very little antibody specific for Giardia; only two sera recognized an antigen with a molecular weight of 31,000 . Because subclinical or mild self-resolving infections are common with Giardia, it is probable that these two individuals had previously had unrecognized infections.

${ }^{125}$ I-labeled trophozoites. ${ }^{125} \mathrm{I}$ labeling of strain WB trophozoites demonstrated that the protein antigen with

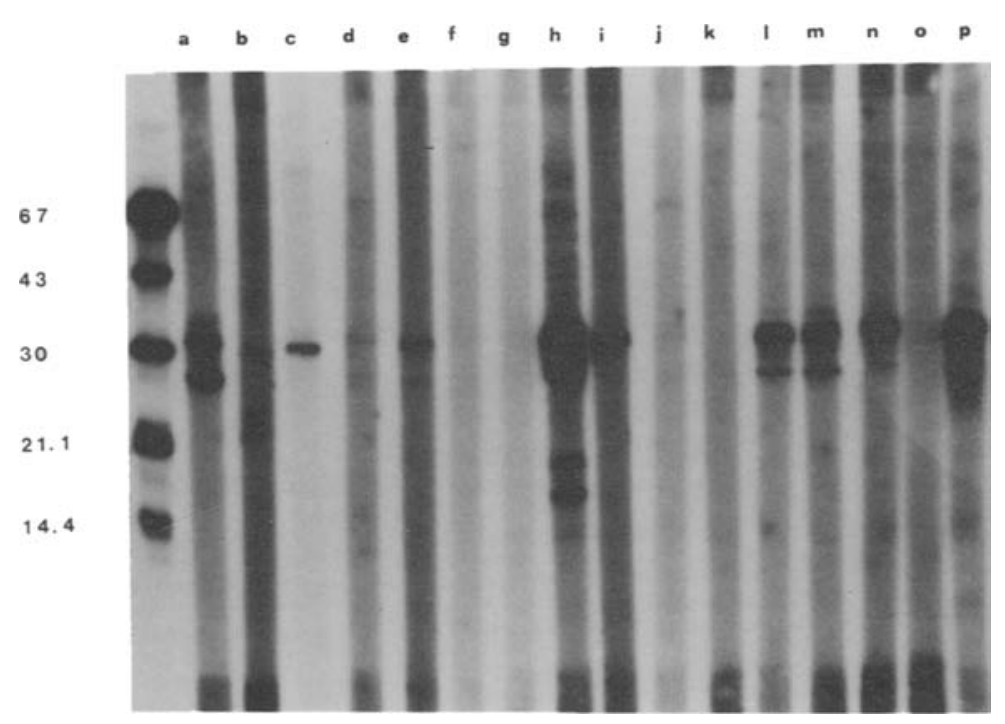

Figure 1. Western immunoblot of a strain WB trophozoite sonicate reacted with sera from patients. Lane a, male, 41, diarrhea acquired in Canada; lane $b$, female, 38, diarrhea, Canada; lane $c$, female, 35, diarrhea, Canada; lane $d$, male, 56, diarrhea, Canada; lane $e$, male, 30, asymptomatic, Africa; lane $f$, male, 3 , chronic diarrhea, IgA deficient, Canada; lane $g$, male, 6 , chronic diarrhea, IgA deficient, Canada; lane ... female, 26, diarrhea, Canada; lane $i$, female, 35, diarrhea, Canada; lane $j$, female, 10 , diarrhea, Canada; lane $k$, male, 76, chronic diarrhea, steroids, Canada; lane $l$, female, 23 , diarrhea, Asia; lane $m$, male, 30 , diarrhea, Soviet Union; lane $n$, female, 22 , diarrhea, Africa; lane o, male, 21, diarrhea, Asia; lane $p$, male, 47, chronic diarrhea, $\operatorname{IgA}$ deficient, Canada. The unmarked lane shows the molecular weight markers. 


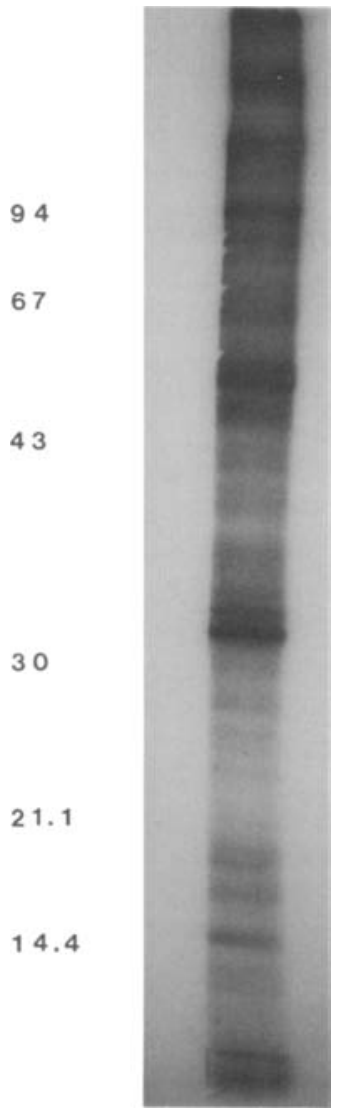

Figure 2. Autoradiograph of ${ }^{125}$ I-labeled WB trophozoites, by SDS-PAGE.

a molecular weight of 31,000 was a major surface-exposed component of the parasite (figure 2). Other major surfacelabeled structures have molecular weights of 55,000 and 80,000 . A protein with a molecular weight of 33,000 was also noted to be labeled with ${ }^{125} \mathrm{I}$; this protein corresponded to the higher molecular-weight component of the 31,000-33,000 antigen doublet frequently recognized in human infections.

\section{Discussion}

Our results have shown a characteristic serological response to natural giardia infection. The major antigen demonstrated was a protein with a molecular weight of 31,000 ; this protein produced a serological response, usually strong, in almost all persons capable of an immune response to acute infection. Other important antigens were found at the molecular weights of $27,000,28,000$, and 56,000 . Although these results involve only a single human strain (WB), we have shown $[12,13]$ that other strains of $G$. lamblia isolated both from humans and from domestic and wild animals (sheep, dog, beaver, muskrat) in one geo- graphic area (Alberta) are antigenically very similar. These data support our use of a single strain as an antigen in this study. Moreover, all of these strains of $G$. lamblia possess a protein antigen with a molecular weight of 31,000 .

Crossley and Holberton [14] characterized the disc cytoskeleton proteins of $G$. lamblia and found that $20 \%$ of the organelle protein was made up of a doublet they named "giardin," which was found to have a molecular weight of 30,000. Our surface-labeling experiment demonstrated the presence of a doublet that we measured to be at a molecular weight of $31,000-33,000$. It would be expected that the major antigen in natural human infection would be a surface-labeled protein, and this expectation suggests that the protein at a molecular weight of 31,000 in 11 of our 12 normal patients is in fact giardin. None of the antigens that produced a serological response in our patients corresponded to the poly-disperse $\left(M_{r} 225,000-\right.$ 94,000 ) excretory-secretory product found in large amounts by Nash et al. [15] on the surface of $G$. lamblia strains WB and PB-1.

Torian et al. [16] prepared murine monoclonal antibodies to $G$. lamblia disc and flagellar proteins with molecular weights of $170,000,155,000,55,000$, and 53,000 . The polypeptides with molecular weights of 55,000 and 53,000 comigrated with bovine brain tubulin and are probably G. lamblia tubulin, a component of both flagellar axonemes and the attachment disc. Our surface-labeling experiment confirmed the presence of a major surface protein with a molecular weight of 55,000. Nine of the sera from normal patients and one serum from a patient with a congenital IgA deficiency contained antibody to an antigen with a molecular weight of 55,000. The response was, however, much weaker than it was to the protein with a molecular weight of 31,000 . Again, surface proteins would be expected to produce a characteristic immune response, so it is possible that the protein with a molecular weight of 55,000 to which our patients responded may be G. lamblia tubulin.

Einfield and Stibbs [17] characterized the trophozoite antigens of four $G$. lamblia strains (including WB) by immunoelectrophoresis, radioiodination, and immunoprecipitation. Proteins recognized by all four strains were found at the molecular weights $130,000,105,000,82,000$, $63,000,55,000,37,000,30,000$, and 24,000 ; the 82,000 component was the most prominent. Monoclonal antibodies specific for the protein with a molecular weight of 82,000 adsorbed to fixed or live parasites and indicated the surface location of the protein. Our surface-labeling experiment confirmed the presence of this protein; however, none of our patients' sera reacted to it, a result suggesting that it is not a major antigen in natural human infection.

In summary, the major $G$. lamblia antigen recognized during human infection was a surface-exposed protein with a molecular weight of 31,000 . This antigen, which may well be the disc component giardin described by earlier workers [14], may be an important epidemiological marker 
for giardiasis. Further studies on larger numbers of patients will, however, be necessary to determine the course of time for developing this antibody and its persistence in the convalescent period.

Geoffrey D. Taylor, Wanda M. Wenman Division of Infectious Diseases, Departments of Medicine and Pediatrics, University of Alberta, Edmonton, Alberta, Canada

\section{References}

1. Myer EA, Jarroll EL. Giardiasis. Am J Epidemiol 1980;111:1-12

2. Keystone JS, Krajden S, Warren MR. Person-to-person transmission of Giardia lamblia in day-care nurseries. Can Med Assoc J 1978;119:241-8

3. Jarroll EL, Bingham AK, Meyer EA. Effect of chlorine on Giardia lamblia cyst viability. Appl Environ Microbiol 1981;41:483-7

4. Owen RL. The immune response in clinical and experimental giardiasis. Trans R Soc Trop Med Hyg 1980;74:443-5

5. Smith PD, Gillin FD, Brown WR, Nash TE. IgG antibody to Giardia lamblia detected by enzyme-linked immunosorbent assay. Gastroenterology 1981;80:1476-80

6. Myer EA. Giardia lamblia isolation and axenic cultivation. Exp Parasitol 1976;39:101-5

7. Smith PD, Gillin FD, Kausha Na, Nash TE. Antigenic analysis of Giardia lamblia from Afganistan, Puerto Rico, Ecuador, and Oregon. Infect Immun 1982;36:714-9
8. Keister DB. Axenic culture of Giardia lamblia in Tyl-S-33 medium supplemented with bile. Trans R Soc Trop Med Hyg 1983;77:487-8

9. Lowry OH, Rosebrough NJ, Farr AL, Randall RJ. Protein measurement with the folinphenol reagent. J Biol Chem 1951;193:265-75

10. Towbin H, Staehelin T, Gordon S. Electrophoretic transfer of proteins from polyacrylamide gels to nitrocellulose sheets: procedure and some applications. Proc Natl Acad Sci USA 1979;76:4350-4

11. Morrison M. Lactoperoxidase-catalyzed, oxidation as a tool for investigation of proteins. Methods Enzymol 1980;70:214-20

12. Meuser RV, Wallis PM, Wenman WM. Antigenic analysis of Giardia. In: Proceedings of the 2nd World Congress on Foodborne Infections and Intoxications. Institute of Veterinary Medicine 1986:402-4

13. Wenman WM, Meuser RV, Wallis PM. Antigenic analysis of Giardia duodenalis strains isolated in Alberta. Can $\mathbf{J}$ Microbiol, 1987 (in press)

14. Crossley R, Holberton DV. Characterization of proteins from the cytoskeleton of Giardia lamblia. J Cel Sci 1983;59: 81-103

15. Nash TE, Gillin FD, Smith PD. Excretory-secretory products of Giardia lamblia. J Immunol 1983;131:2004-10

16. Torian BE, Barnes RC, Stephens RS, Stibbs HH. Tubulin and high-molecular-weight polypeptides as Giardia lamblia antigens. Infect Immun 1984;46:152-8

17. Einfield DA, Stibbs HH. Identification and characterization of a major surface antigen of Giardia lamblia. Infect Immun 1984;46:377-83

THE JOURNAL OF INFECTIOUS DISEASES - VOL. 155, NO. 1 - JANUARY 1987 (C) 1987 by The University of Chicago. All rights reserved. 0022-1899/87/5501-0019\$01.00

\section{Human Enteric Coronaviruses: Further Characterization and Immunoblotting of Viral Proteins}

Strains of coronavirus (CV) can be responsible for acute diarrhea in different animal species [1]. The enteropathogenic role of CVs in humans, however, has not been definitely established. Evidence for association of $\mathrm{CV}$ infection and gastroenteritis in man has been obtained mainly by using electron microscopy to detect CV-like particles in the feces of patients with diarrhea [2-4]. Because

Received for publication 2 April 1986, and in revised form 8 July 1986.

This work was supported by grant GRT C6-181/124 from the World Health Organization and by funds from the Ministero della Pubblica Istruzione (Ricerca Scientifica).

We thank Maria Mastrosimone for help in the English revision.

Please address requests for reprints to Dr. Giuseppe Gerna, Virus Laboratory, Institute of Infectious Diseases, University of Pavia, 27ion Pavia, Italy. of the extreme difficulty with isolation and propagation in tissue culture, the candidate human enteric CVs (HECVs) have not been adequately characterized. Recently, we reported the possible implication of HECV strains in acute infantile gastroenteritis [5]. By immune electron microscopy (IEM) these strains appeared to be antigenically related to human coronavirus (HCV) OC43, a known respiratory pathogenic virus, but further characterization of the HECV strains was hampered by failure to isolate and propagate them in tissue culture. Beards et al. [6] described other fringed pleomorphic viral particles detected by electron microscopy in stools from children and adults with diarrhea. These viral particles were morphologically more similar to toroviruses of the Berne-Breda group (to which they were shown by IEM to be antigenically related) than to typical CVs. In this report, we attempted further characterization of two HECV strains purified from stools 